\title{
Nonlinear algorithms approach to split common solution problems
}

\section{Zhenhua He ${ }^{1}$ and Wei-Shih Du ${ }^{2^{*}}$}

\section{"Correspondence:}

wsdu@nknucc.nknu.edu.tw

${ }^{2}$ Department of Mathematics,

National Kaohsiung Normal

University, Kaohsiung, 824, Taiwan

Full list of author information is

available at the end of the article

\begin{abstract}
In this paper, we introduce some new iterative algorithms for the split common solution problems for equilibrium problems and fixed point problems of nonlinear mappings. Some examples illustrating our results are also given.
\end{abstract}

MSC: 47J25; 47H09; 65K10

Keywords: fixed point problem; iterative algorithm; equilibrium problem; split common solution problem

\section{Introduction}

Throughout this paper, we assume that $H$ is a real Hilbert space with zero vector $\theta$, whose inner product and norm are denoted by $\langle\cdot, \cdot\rangle$ and $\|\cdot\|$, respectively. Let $K$ be a nonempty subset of $H$ and $T$ be a mapping from $K$ into itself. The set of fixed points of $T$ is denoted by $\mathcal{F}(T)$. The symbols $\mathbb{N}$ and $\mathbb{R}$ are used to denote the sets of positive integers and real numbers, respectively.

Let $C$ and $K$ be nonempty subsets of real Banach spaces $E_{1}$ and $E_{2}$, respectively. Let $A: E_{1} \rightarrow E_{2}$ be a bounded linear mapping, $T$ a mapping from $C$ into itself with $\mathcal{F}(T) \neq \emptyset$ and $f$ a bi-function from $K \times K$ into $\mathbb{R}$. The classical equilibrium problem is to find $x \in K$ such that

$$
f(x, y) \geq 0, \quad \forall y \in K
$$

The symbol $E P(f)$ is used to denote the set of all solutions of the problem (1.1), that is,

$$
E P(f)=\{u \in K: f(u, v) \geq 0, \forall v \in K\} .
$$

The equilibrium problem contains optimization problems, variational inequalities problems, saddle point problems, the Nash equilibrium problems, fixed point problems, complementary problems, bilevel problems, and semi-infinite problems as special cases and have many applications in mathematical program with equilibrium constraint; for detail, one can refer to [1-4] and references therein.

In this paper, we study the following split common solution problem (SCSP) for equilibrium problems and fixed point problems of nonlinear mappings $A, T$ and $f$ :

(c) $2012 \mathrm{He}$ and Du; licensee Springer. This is an Open Access article distributed under the terms of the Creative Commons Attribution License (http://creativecommons.org/licenses/by/2.0), which permits unrestricted use, distribution, and reproduction in any medium, provided the original work is properly cited. 
(SCSP) Find $p \in C$ such that $p \in \mathcal{F}(T)$ and $u:=A p \in K$ which satisfies $f(u, v) \geq 0, \forall v \in K$. The solution set of (SCSP) is denoted by

$$
\Gamma=\{p \in \mathcal{F}(T): A p \in E P(f)\}
$$

Many authors had proposed some methods to find the solution of the equilibrium problem (1.1). As a generalization of the equilibrium problem (1.1), finding a common solution for some equilibrium problems and fixed point problems of nonlinear operators, it has been considered in the same subset of the same space; see [5-15]. However, some equilibrium problems and fixed point problems of nonlinear mappings always belong to different subsets of spaces in general. So the split common solution is very important for the research on generalized equilibriums problems and fixed point problems.

Example 1.1 Let $E_{1}=E_{2}=\mathbb{R}, C:=[1,+\infty)$ and $K:=(-\infty,-2]$. Let $A(x)=-2 x$ for all $x \in \mathbb{R}$ and $T x=\frac{2 x}{x+1}$ for all $x \in C$. Let $f: K \times K \rightarrow \mathbb{R}$ be define by $f(u, v)=2(u-v)$ for all $u, v \in K$. Clearly, $A$ is a bounded linear operator, $\mathcal{F}(T)=\{1\}$ and $A(1)=-2 \in E P(f)$. So $\Gamma=\{p \in$ $\mathcal{F}(T): A p \in E P(f)\} \neq \emptyset$.

Example 1.2 Let $E_{1}=\mathbb{R}^{2}$ with the norm $\|\alpha\|=\left(a_{1}^{2}+a_{2}^{2}\right)^{\frac{1}{2}}$ for $\alpha=\left(a_{1}, a_{2}\right) \in \mathbb{R}^{2}$ and $E_{2}=\mathbb{R}$ with the standard norm $|\cdot|$. Let $C:=\left\{\alpha=\left(a_{1}, a_{2}\right) \in \mathbb{R}^{2} \mid a_{1}^{2}+a_{2}^{2} \leq 1\right\}$ and $K:=[-2,2]$. Let $A \alpha=-2 a_{1}$ for $\alpha=\left(a_{1}, a_{2}\right) \in E_{1}$ and $T \alpha=\left(a_{1}^{2}, a_{2}^{2}\right)$ for all $\alpha=\left(a_{1}, a_{2}\right) \in C$. Then $\mathcal{F}(T)=$ $\{(0,1),(1,0),(0,0)\}$ and $A$ is a bounded and linear operator from $E_{1}$ into $E_{2}$ with $\|A\|=2$. Now define a bi-function $f$ as $f(u, v)=v-u$ for all $u, v \in K$. Then $f$ is a bi-function from $K \times K$ into $\mathbb{R}$ with $E P(f)=\{-2\}$.

$$
\text { Clearly, } p=(1,0) \in \mathcal{F}(T), A p=-2 \in E P(f) \text {. So } \Gamma=\{p \in \mathcal{F}(T): A p \in E P(f)\} \neq \emptyset \text {. }
$$

Remark 1.1 It is worth to mention that the split common solution problem in Example 1.1 lies in two different subsets of the same space and the split common solution problem in Example 1.2 lies in two different subsets of the different space. So, Examples 1.1 and 1.2 also show that the split common solution problem is meaningful.

In this paper, we introduce a weak convergence algorithm and a strong convergence algorithm for the split common solution problem when the nonlinear operator $T$ is a quasinonexpansive mapping. Some strong and weak convergence theorems are established. We also give some examples to illustrate our results.

\section{Preliminaries}

We write $x_{n} \rightarrow x$ to indicate that the sequence $\left\{x_{n}\right\}$ weakly converges to $x$ and $x_{n} \rightarrow x$ will symbolize strong convergence as usual.

A Banach space $(X,\|\cdot\|)$ is said to satisfy Opial's condition, if for each sequence $\left\{x_{n}\right\}$ in $X$ which converges weakly to a point $x \in X$, we have

$$
\liminf _{n \rightarrow \infty}\left\|x_{n}-x\right\|<\liminf _{n \rightarrow \infty}\left\|x_{n}-y\right\|, \quad \forall y \in X, y \neq x .
$$

It is well known that any Hilbert space satisfies Opial's condition.

Let $K$ be a nonempty subset of real Hilbert spaces $H$. Recall that a mapping $T: K \rightarrow K$ is said to be nonexpansive if $\|T x-T y\| \leq\|x-y\|$ for all $x, y \in K$ and quasi-nonexpansive if $\mathcal{F}(T) \neq \emptyset$ and $\|T x-T p\| \leq\|x-p\|$ for all $x \in K, p \in \mathcal{F}(T)$. 
Example 2.1 Let $H=\mathbb{R}$ with the inner product defined by $\langle x, y\rangle=x y$ for all $x, y \in \mathbb{R}$ and the standard norm $|\cdot|$. Let $C:=[0,+\infty)$ and $T x=\frac{x^{2}+2}{1+x}$ for all $x \in C$. Obviously, $\mathcal{F}(T)=\{2\}$. It is easy to see that

$$
|T x-2|=\frac{x}{1+x}|x-2| \leq|x-2| \quad \text { for } x \in C
$$

and

$$
\left|T(0)-T\left(\frac{1}{3}\right)\right|=\frac{5}{12}>\left|0-\frac{1}{3}\right| .
$$

Hence, $T$ is a continuous quasi-nonexpansive mapping but not nonexpansive.

Definition 2.1 (see [16]) Let $K$ be a nonempty closed convex subset of a real Hilbert space $H$ and $T$ a mapping from $K$ into $K$. The mapping $T$ is said to be demiclosed if, for any sequence $\left\{x_{n}\right\}$ which weakly converges to $y$, and if the sequence $\left\{T x_{n}\right\}$ strongly converges to $z$, then $T y=z$.

Remark 2.1 In Definition 2.1, the particular case of demiclosedness at zero is frequently used in some iterative convergence algorithms, which is the particular case when $z=\theta$, the zero vector of $H$; for more detail, one can refer to [16].

The following concept of zero-demiclosedness was introduced in [17].

Definition 2.2 (see [17]) Let $K$ be a nonempty, closed, and convex subset of a real Hilbert space and $T$ a mapping from $K$ into $K$. The mapping $T$ is called zero-demiclosed if $\left\{x_{n}\right\}$ in $K$ satisfying $\left\|x_{n}-T x_{n}\right\| \rightarrow 0$ and $x_{n} \rightarrow z \in K$ implies $T z=z$.

The following result was essentially proved in [17], but we give the proof for the sake of completeness.

Proposition 2.1 Let $K$ be a nonempty, closed, and convex subset of a real Hilbert space with zero vector $\theta$ and $T$ a mapping from $K$ into $K$. Then the following statements hold.

(a) $T$ is zero-demiclosed if and only if $I-T$ is demiclosed at $\theta$;

(b) If $T$ is a nonexpansive mappings and there is a bounded sequence $\left\{x_{n}\right\} \subset H$ such that $\left\|x_{n}-T x_{n}\right\| \rightarrow 0$ as $n \rightarrow 0$, then $T$ is zero-demiclosed.

Proof Obviously, the conclusion (a) holds. To see (b), since $\left\{x_{n}\right\}$ is bounded, there is a subsequence $\left\{x_{n_{k}}\right\} \subset\left\{x_{n}\right\}$ and $z \in H$ such that $x_{n_{k}} \rightarrow z$. One can claim $T z=z$. Indeed, if $T z \neq z$, it follows from the Opial's condition that

$$
\begin{aligned}
\liminf _{k \rightarrow \infty}\left\|x_{n_{k}}-z\right\| & <\liminf _{k \rightarrow \infty}\left\|x_{n_{k}}-T z\right\| \\
& \leq \liminf _{k \rightarrow \infty}\left\{\left\|x_{n_{k}}-T x_{n_{k}}\right\|+\left\|T x_{n_{k}}-T z\right\|\right\} \\
& =\liminf _{k \rightarrow \infty}\left\|T x_{n_{k}}-T z\right\| \\
& \leq \liminf _{k \rightarrow \infty}\left\|x_{n_{k}}-z\right\|,
\end{aligned}
$$

which is a contradiction. So $T z=z$ and hence $T$ is zero-demiclosed. 
Example 2.2 Let $H, C$, and $T$ be the same as in Example 2.1. Let $\left\{x_{n}\right\}$ be a sequence in $C$. If $x_{n} \rightarrow z$ and $x_{n}-T x_{n} \rightarrow 0$, then $z \in F(T)=\{2\}$. Indeed, since $T$ is continuous, we have $T z=z$ and $z \in F(T)=\{2\}$. Hence, $T$ is zero-demiclosed.

Example 2.3 Let $H=\mathbb{R}$ with the inner product defined by $\langle x, y\rangle=x y$ for all $x, y \in \mathbb{R}$ and the standard norm $|\cdot|$. Let $C:=[0,+\infty)$. Let $T$ be a mapping from $C$ into $C$ defined by

$$
T x= \begin{cases}\frac{2 x}{x^{2}+1}, & x \in(1,+\infty), \\ 0, & x \in[0,1] .\end{cases}
$$

Then $T$ is a discontinuous quasi-nonexpansive mapping but not zero-demiclosed.

Proof Obviously, $\mathcal{F}(T)=\{0\}$, and $T$ is a quasi-nonexpansive operator. On the other hand, let $x_{n}=1+\frac{1}{n}$ for all $n \in \mathbb{N}$, then it is not hard to prove that $x_{n} \rightarrow 1, x_{n}-T x_{n} \rightarrow 0$ and $1 \notin \mathcal{F}(T)$. So $T$ is not zero-demiclosed.

Let $H_{1}$ and $H_{2}$ be two Hilbert spaces. Let $A: H_{1} \rightarrow H_{2}$ and $B: H_{2} \rightarrow H_{1}$ be two bounded linear operators. $B$ is called the adjoint operator (or adjoint) of $A$, if for all $z \in H_{1}, w \in$ $H_{2}, B$ satisfies $\langle A z, w\rangle=\langle z, B w\rangle$. It is known that the adjoint operator of a bounded linear operator on a Hilbert space always exists and is bounded linear and unique. Moreover, it is not hard to show that if $B$ is an adjoint operator of $A$, then $\|A\|=\|B\|$.

Example 2.4 Let $H_{1}=\mathbb{R}^{3}$ with the norm $\|\alpha\|=\left(a_{1}^{2}+a_{2}^{2}+a_{3}^{2}\right)^{\frac{1}{2}}$ for $\alpha=\left(a_{1}, a_{2}, a_{3}\right) \in \mathbb{R}^{2}$ and $H_{2}=\mathbb{R}^{4}$ with the norm $\|\gamma\|=\left(c_{1}^{2}+c_{2}^{2}+c_{3}^{2}+c_{4}^{2}\right)^{\frac{1}{2}}$ for $\gamma=\left(c_{1}, c_{2}, c_{3}, c_{4}\right) \in \mathbb{R}^{4}$. Let $\langle\alpha, \beta\rangle=a_{1} b_{1}+a_{2} b_{2}+a_{3} b_{3}$ and $\langle\gamma, \eta\rangle=c_{1} d_{1}+c_{2} d_{2}+c_{3} d_{3}+c_{4} d_{4}$ denote the inner product of $H_{1}$ and $H_{2}$, respectively, where $\alpha=\left(a_{1}, a_{2}, a_{3}\right), \beta=\left(b_{1}, b_{2}, b_{3}\right) \in H_{1}, \gamma=\left(c_{1}, c_{2}, c_{3}, c_{4}\right)$, $\eta=\left(d_{1}, d_{2}, d_{3}, d_{4}\right) \in H_{2}$. Let $A \alpha=\left(a_{3}, a_{1}+a_{2}, a_{1}-a_{2}, a_{3}\right)$ for $\alpha=\left(a_{1}, a_{2}, a_{3}\right) \in H_{1}$. Then $A$ is a bounded linear operator from $H_{1}$ into $H_{2}$ with $\|A\|=\sqrt{2}$. For $\gamma=\left(c_{1}, c_{2}, c_{3}, c_{4}\right) \in H_{2}$, let $B \gamma=\left(c_{2}+c_{3}, c_{2}-c_{3}, c_{1}+c_{4}\right)$. Then $B$ is a bounded linear operator from $H_{2}$ into $H_{1}$ with $\|B\|=\sqrt{2}$. Moreover, for any $\alpha=\left(a_{1}, a_{2}, a_{3}\right) \in H_{1}$ and $\gamma=\left(c_{1}, c_{2}, c_{3}, c_{4}\right) \in H_{2}$, $\langle A \alpha, \gamma\rangle=\langle\alpha, B \gamma\rangle$, so $B$ is an adjoint operator of $A$.

Let $K$ be a closed and convex subset of a real Hilbert space $H$. For each point $x \in H$, there exists a unique nearest point in $K$, denoted by $P_{K} x$, such that $\left\|x-P_{K} x\right\| \leq\|x-y\|$, $\forall y \in K$. The mapping $P_{K}$ is called the metric projection from $H$ onto $K$. It is well known that $P_{K}$ has the following characterizations:

(i) $\left\langle x-y, P_{K} x-P_{K} y\right\rangle \geq\left\|P_{K} x-P_{K} y\right\|^{2}$ for every $x, y \in H$.

(ii) for $x \in H$, and $z \in K, z=P_{K}(x) \Longleftrightarrow\langle x-z, z-y\rangle \geq 0, \forall y \in K$.

(iii) $\left\|y-P_{K}(x)\right\|^{2}+\left\|x-P_{K}(x)\right\|^{2} \leq\|x-y\|^{2}$ for all $x \in H$ and $y \in K$.

The following lemmas are crucial in our proofs.

Lemma 2.1 (see [1]) Let $K$ be a nonempty, closed, and convex subset of $H$ and $F$ be a bifunction of $K \times K$ into $\mathbb{R}$ satisfying the following conditions.

(A1) $F(x, x)=0$ for all $x \in K$;

(A2) $F$ is monotone, that is, $F(x, y)+F(y, x) \leq 0$ for all $x, y \in K$;

(A3) for each $x, y, z \in K, \lim \sup _{t \downarrow 0} F(t z+(1-t) x, y) \leq F(x, y)$;

(A4) for each $x \in K, y \mapsto F(x, y)$ is convex and lower semicontinuous. 
Let $r>0$ and $x \in H$. Then there exists $z \in K$ such that $F(z, y)+\frac{1}{r}\langle y-z, z-x\rangle \geq 0$, for all $y \in K$.

Lemma 2.2 (see [3]) Let $K$ be a nonempty, closed, and convex subset of $H$ and let $F$ be a bi-function of $K \times K$ into $\mathbb{R}$ satisfying (A1)-(A4). For $r>0$, define a mapping $T_{r}^{F}: H \rightarrow K$ as follows:

$$
T_{r}^{F}(x)=\left\{z \in K: F(z, y)+\frac{1}{r}\langle y-z, z-x\rangle \geq 0, \forall y \in K\right\}
$$

for all $x \in H$. Then the following hold:

(i) $T_{r}^{F}$ is single-valued and $F\left(T_{r}^{F}\right)=E P(F)$ for any $r>0$ and $E P(F)$ is closed and convex;

(ii) $T_{r}^{F}$ is firmly nonexpansive, that is, for any $x, y \in H$, $\left\|T_{r}^{F} x-T_{r}^{F} y\right\|^{2} \leq\left\langle T_{r}^{F} x-T_{r}^{F} y, x-y\right\rangle$.

Lemma 2.3 (see, e.g., [9]) Let $H$ be a real Hilbert space. Then the following hold.

(a) $\|x+y\|^{2} \leq\|y\|^{2}+2\langle x, x+y\rangle$ and $\|x-y\|^{2}=\|x\|^{2}+\|y\|^{2}-2\langle x, y\rangle$ for all $x, y \in H$;

(b) $\|\alpha x+(1-\alpha) y\|^{2}=\alpha\|x\|^{2}+(1-\alpha)\|y\|^{2}-\alpha(1-\alpha)\|x-y\|^{2}$ for all $x, y \in H$ and $\alpha \in[0,1]$.

The following result is simple, but it is very useful in this paper; see also [18].

Lemma 2.4 Let the mapping $T_{r}^{F}$ be defined as (2.1). Then for $r, s>0$ and $x, y \in H$,

$$
\left\|T_{r}^{F}(x)-T_{s}^{F}(y)\right\| \leq\|x-y\|+\frac{|s-r|}{s}\left\|T_{s}^{F}(y)-y\right\| .
$$

In particular, $\left\|T_{r}^{F}(x)-T_{r}^{F}(y)\right\| \leq\|x-y\|$ for any $r>0$ and $x, y \in H$, that is $T_{r}^{F}$ is nonexpansive for any $r>0$.

Proof For $r, s>0$ and $x, y \in H$, by (i) of Lemma 2.2, $T_{r}^{F}(x)=z_{1}$ and $T_{s}^{F}(y)=z_{2}$ for some $z_{1}, z_{2} \in K$. By the definition of $T_{r}^{F}$, we have

$$
F\left(z_{1}, u\right)+\frac{1}{r}\left\langle u-z_{1}, z_{1}-x\right\rangle \geq 0, \quad \forall u \in K
$$

and

$$
F\left(z_{2}, u\right)+\frac{1}{s}\left\langle u-z_{2}, z_{2}-y\right\rangle \geq 0, \quad \forall u \in K
$$

So, combining (2.2), (2.3), and (A2), we get

$$
\frac{1}{r}\left\langle z_{2}-z_{1}, z_{1}-x\right\rangle+\frac{1}{s}\left\langle z_{1}-z_{2}, z_{2}-y\right\rangle \geq 0
$$

or

$$
\left\langle z_{2}-z_{1}, \frac{z_{1}-x}{r}\right\rangle-\left\langle z_{2}-z_{1}, \frac{z_{2}-y}{s}\right\rangle \geq 0
$$


or

$$
\left\langle z_{2}-z_{1}, \frac{s}{r}\left(z_{1}-x\right)\right\rangle-\left\langle z_{2}-z_{1}, z_{2}-y\right\rangle \geq 0
$$

or

$$
\left\langle z_{2}-z_{1}, z_{1}-x-\frac{r}{s}\left(z_{2}-y\right)\right\rangle \geq 0
$$

or

$$
\left\langle z_{2}-z_{1}, z_{1}-z_{2}+z_{2}-x-\frac{r}{s}\left(z_{2}-y\right)\right\rangle \geq 0
$$

which implies

$$
\left\|z_{2}-z_{1}\right\|^{2} \leq\left\langle z_{2}-z_{1}, z_{2}-x-\frac{r}{s}\left(z_{2}-y\right)\right\rangle \leq\left\|z_{2}-z_{1}\right\|\left\|z_{2}-x-\frac{r}{s}\left(z_{2}-y\right)\right\|
$$

and hence

$$
\begin{aligned}
\left\|T_{r}^{F}(x)-T_{s}^{F}(y)\right\| & =\left\|z_{2}-z_{1}\right\| \\
& \leq\left\|z_{2}-x-\frac{r}{s}\left(z_{2}-y\right)\right\| \\
& \leq\|y-x\|+\left\|\left(1-\frac{r}{s}\right)\left(z_{2}-y\right)\right\| \\
& =\|y-x\|+\frac{|s-r|}{s}\left\|T_{s}^{F}(y)-y\right\| .
\end{aligned}
$$

In particular, the last inequality show that for any $r>0, T_{r}^{F}$ is nonexpansive. The proof is completed.

\section{Main results}

In this section, we first introduce a weak convergence iterative algorithms for the split common solution problem.

Theorem 3.1 Let $H_{1}$ and $H_{2}$ be two real Hilbert spaces and $C \subset H_{1}$ and $K \subset H_{2}$ be two nonempty closed convex sets. Let $T: C \rightarrow C$ be zero-demiclosed quasi-nonexpansive mappings and $f: K \times K \rightarrow \mathbb{R}$ be bi-functions with $\Gamma=\{p \in F(T): A p \in E P(f)\} \neq \emptyset$. Let $A: H_{1} \rightarrow H_{2}$ be a bounded linear operator with its adjoint $B$.

Given $x_{1} \in C$ and $\eta \in(0,1)$. Let $\left\{x_{n}\right\}$ and $\left\{u_{n}\right\}$ be sequences generated by

$$
\left\{\begin{array}{l}
u_{n}=T_{r_{n}}^{f} A x_{n}, \\
x_{n+1}=\left(1-\alpha_{n}\right) y_{n}+\alpha_{n} T y_{n}, \\
y_{n}=P_{C}\left(x_{n}+\varepsilon B\left(T_{r_{n}}^{f}-I\right) A x_{n}\right), \quad \forall n \in \mathbb{N},
\end{array}\right.
$$

where $\left\{r_{n}\right\} \subset(0,+\infty)$ with $\liminf _{n \rightarrow \infty} r_{n}>0, \varepsilon \in\left(0, \frac{1}{\|B\|^{2}}\right)$ is a constant, $P_{C}$ is a projection operator from $H_{1}$ into $C$ and $\left\{\alpha_{n}\right\}$ satisfies $\alpha_{n} \in[\eta, 1-\eta]$ for $n \in \mathbb{N}$. Then $x_{n} \rightarrow p \in \Gamma$ and $u_{n} \rightarrow A p \in E P(f)$. 
Proof Let $x^{*} \in \Gamma$. Then $A x^{*} \in E P(f)$. For each $n \in \mathbb{N}$, by Lemmas 2.2 and 2.3, we have

$$
\begin{aligned}
\left\|T_{r_{n}}^{f} A x_{n}-T_{r_{n}}^{f} A x^{*}\right\|^{2} & \leq\left\langle T_{r_{n}}^{f} A x_{n}-T_{r_{n}}^{f} A x^{*}, A x_{n}-A x^{*}\right\rangle \\
& =\frac{1}{2}\left\{\left\|T_{r_{n}}^{f} A x_{n}-A x^{*}\right\|^{2}+\left\|A x_{n}-A x^{*}\right\|^{2}-\left\|T_{r_{n}}^{f} A x_{n}-A x_{n}\right\|^{2}\right\} .
\end{aligned}
$$

So,

$$
\left\|T_{r_{n}}^{f} A x_{n}-A x^{*}\right\|^{2} \leq\left\|A x_{n}-A x^{*}\right\|^{2}-\left\|T_{r_{n}}^{f} A x_{n}-A x_{n}\right\|^{2} \quad \text { for any } n \in \mathbb{N} \text {. }
$$

By (b) of Lemma 2.3 and (3.2), for each $n \in \mathbb{N}$, we get

$$
\begin{aligned}
& 2 \varepsilon\left\langle x_{n}-x^{*}, B\left(T_{r_{n}}^{f}-I\right) A x_{n}\right\rangle \\
& \quad=2 \varepsilon\left(A\left(x_{n}-x^{*}\right)+\left(T_{r_{n}}^{f}-I\right) A x_{n}-\left(T_{r_{n}}^{f}-I\right) A x_{n},\left(T_{r_{n}}^{f}-I\right) A x_{n}\right\rangle \\
& \quad=2 \varepsilon\left(\frac{1}{2}\left\|T_{r_{n}}^{f} A x_{n}-A x^{*}\right\|^{2}+\frac{1}{2}\left\|\left(T_{r_{n}}^{f}-I\right) A x_{n}\right\|^{2}-\frac{1}{2}\left\|A x_{n}-A x^{*}\right\|^{2}-\left\|\left(T_{r_{n}}^{f}-I\right) A x_{n}\right\|^{2}\right) \\
& \quad \leq 2 \varepsilon\left(\frac{1}{2}\left\|\left(T_{r_{n}}^{f}-I\right) A x_{n}\right\|^{2}-\left\|\left(T_{r_{n}}^{f}-I\right) A x_{n}\right\|^{2}\right)=-\varepsilon\left\|\left(T_{r_{n}}^{f}-I\right) A x_{n}\right\|^{2}
\end{aligned}
$$

Note that for any $n \in \mathbb{N}$,

$$
\left\|B\left(T_{r_{n}}^{f}-I\right) A x_{n}\right\|^{2} \leq\|B\|^{2}\left\|\left(T_{r_{n}}^{f}-I\right) A x_{n}\right\|^{2},
$$

so it follows from (3.1), (3.3), and (3.4) that

$$
\begin{aligned}
& \left\|x_{n+1}-x^{*}\right\|^{2} \\
& \quad=\left(1-\alpha_{n}\right)\left\|y_{n}-x^{*}\right\|^{2}+\alpha_{n}\left\|T y_{n}-x^{*}\right\|^{2}-\left(1-\alpha_{n}\right) \alpha_{n}\left\|y_{n}-T y_{n}\right\|^{2} \\
& \quad \leq\left\|y_{n}-x^{*}\right\|^{2}-\eta^{2}\left\|y_{n}-T y_{n}\right\|^{2} \\
& \quad=\left\|P_{C}\left(x_{n}+\varepsilon B\left(T_{r_{n}}^{f}-I\right) A x_{n}\right)-P_{C} x^{*}\right\|^{2}-\eta^{2}\left\|y_{n}-T y_{n}\right\|^{2} \\
& \quad \leq\left\|x_{n}+\varepsilon B\left(T_{r_{n}}^{f}-I\right) A x_{n}-x^{*}\right\|^{2}-\eta^{2}\left\|y_{n}-T y_{n}\right\|^{2} \\
& \quad=\left\|x_{n}-x^{*}\right\|^{2}+\left\|\varepsilon B\left(T_{r_{n}}^{f}-I\right) A x_{n}\right\|^{2}+2 \varepsilon\left(x_{n}-x^{*}, B\left(T_{r_{n}}^{f}-I\right) A x_{n}\right\rangle-\eta^{2}\left\|y_{n}-T y_{n}\right\|^{2} \\
& \quad \leq\left\|x_{n}-x^{*}\right\|^{2}+\varepsilon^{2}\|B\|^{2}\left\|\left(T_{r_{n}}^{f}-I\right) A x_{n}\right\|^{2}-\varepsilon\left\|\left(T_{r_{n}}^{f}-I\right) A x_{n}\right\|^{2}-\eta^{2}\left\|y_{n}-T y_{n}\right\|^{2} \\
& \quad=\left\|x_{n}-x^{*}\right\|^{2}-\varepsilon\left(1-\varepsilon\|B\|^{2}\right)\left\|\left(T_{r_{n}}^{f}-I\right) A x_{n}\right\|^{2}-\eta^{2}\left\|y_{n}-T y_{n}\right\|^{2} .
\end{aligned}
$$

Since $\varepsilon \in\left(0, \frac{1}{\|B\|^{2}}\right), \varepsilon\left(1-\varepsilon\|B\|^{2}\right)>0$, by (3.5), we obtain

$$
\left\|x_{n+1}-x^{*}\right\| \leq\left\|y_{n}-x^{*}\right\| \leq\left\|x_{n}-x^{*}\right\|
$$

and

$$
\begin{aligned}
& \eta^{2}\left\|y_{n}-T y_{n}\right\|^{2}+\varepsilon\left(1-\varepsilon\|B\|^{2}\right)\left\|\left(T_{r_{n}}^{f}-I\right) A x_{n}\right\|^{2} \\
& \quad \leq\left\|x_{n}-x^{*}\right\|^{2}-\left\|x_{n+1}-x^{*}\right\|^{2} \quad \text { for any } n \in \mathbb{N} .
\end{aligned}
$$


The inequality (3.6) implies that $\lim _{n \rightarrow \infty}\left\|x_{n}-x^{*}\right\|$ exists. Further, from (3.6) and (3.7), we get

$$
\begin{aligned}
& \lim _{n \rightarrow \infty}\left\|x_{n}-x^{*}\right\|=\lim _{n \rightarrow \infty}\left\|y_{n}-x^{*}\right\|, \\
& \lim _{n \rightarrow \infty}\left\|y_{n}-T y_{n}\right\|=0
\end{aligned}
$$

and

$$
\lim _{n \rightarrow \infty}\left\|\left(T_{r_{n}}^{f}-I\right) A x_{n}\right\|=0 .
$$

From (3.1) and (3.10), we have

$$
\begin{aligned}
\left\|y_{n}-x_{n}\right\| & =\left\|P_{C}\left(x_{n}+\varepsilon B\left(T_{r_{n}}^{f}-I\right) A x_{n}\right)-P_{C} x_{n}\right\| \\
& \leq \varepsilon\left\|B\left(T_{r_{n}}^{f}-I\right) A x_{n}\right\| \rightarrow 0 \quad \text { as } n \rightarrow \infty .
\end{aligned}
$$

Since $\lim _{n \rightarrow \infty}\left\|x_{n}-x^{*}\right\|$ exists, $\left\{x_{n}\right\}$ is bounded and hence $\left\{x_{n}\right\}$ has a weakly convergence subsequence $\left\{x_{n_{j}}\right\}$. Assume that $x_{n_{j}} \rightarrow p$ for some $p \in C$. Then $A x_{n_{j}} \rightarrow A p \in K, y_{n_{j}} \rightarrow p$ and $T_{r_{n_{j}}}^{f} A x_{n_{j}} \rightarrow A p$ by (3.10) and (3.11).

We argue $p \in \Gamma$. Since $T$ is a zero-demiclosed mapping, by (3.9) and $y_{n_{j}} \rightarrow p$, we obtain $p \in \mathcal{F}(T)$. Applying Lemma 2.2, $E P(f)=\mathcal{F}\left(T_{r}^{f}\right)$ for any $r>0$. We claim $T_{r}^{f} A p=A p$. If $T_{r}^{f} A p \neq A p$, since $A x_{n}-T_{r_{n}}^{f} A x_{n}=\left(I-T_{r_{n}}^{f}\right) A x_{n} \rightarrow 0$ as $n \rightarrow \infty$ from (3.10) and applying Opial's condition, we have

$$
\begin{aligned}
& \liminf _{j \rightarrow \infty}\left\|A x_{n_{j}}-A p\right\| \\
& \quad<\liminf _{j \rightarrow \infty}\left\|A x_{n_{j}}-T_{r}^{f} A p\right\| \\
& \quad=\liminf _{j \rightarrow \infty}\left\|A x_{n_{j}}-T_{r_{n_{j}}}^{f} A x_{n_{j}}+T_{r_{n_{j}}}^{f} A x_{n_{j}}-T_{r}^{f} A p\right\| \\
& \quad \leq \liminf _{j \rightarrow \infty}\left\{\left\|A x_{n_{j}}-T_{r_{n_{j}}}^{f} A x_{n_{j}}\right\|+\left\|T_{r_{n_{j}}}^{f} A x_{n_{j}}-T_{r}^{f} A p\right\|\right\} \\
& \quad=\liminf _{j \rightarrow \infty}\left\|T_{r_{n_{j}}}^{f} A x_{n_{j}}-T_{r}^{f} A p\right\| \\
& \quad=\liminf _{j \rightarrow \infty}\left\|T_{r}^{f} A p-T_{r_{n_{j}}}^{f} A x_{n_{j}}\right\| \\
& \quad \leq \liminf _{j \rightarrow \infty}\left(\left\|A x_{n_{j}}-A p\right\|+\frac{\left|r_{n_{j}}-r\right|}{r_{n_{j}}}\left\|T_{r_{n_{j}}}^{f} A x_{n_{j}}-A x_{n_{j}}\right\|\right) \quad \text { (by Lemma 2.4) } \\
& \quad=\liminf _{j \rightarrow \infty}\left\|A x_{n_{j}}-A p\right\|,
\end{aligned}
$$

which lead to a contradiction. So $A p \in F\left(T_{r}^{f}\right)=E P(f)$, and hence we show $p \in \Gamma$.

Now, we prove $\left\{x_{n}\right\}$ converges weakly to $p \in \Gamma$. Otherwise, if there exists other subsequence of $\left\{x_{n}\right\}$ which is denoted by $\left\{x_{n_{l}}\right\}$ such that $x_{n_{l}} \rightarrow q \in \Gamma$ with $q \neq p$. Then, by Opial's condition,

$$
\liminf _{l \rightarrow \infty}\left\|x_{n_{l}}-q\right\|<\liminf _{l \rightarrow \infty}\left\|x_{n_{l}}-p\right\|<\liminf _{l \rightarrow \infty}\left\|x_{n_{l}}-q\right\| .
$$

This is a contradiction. Hence, $\left\{x_{n}\right\}$ converges weakly to an element $p \in \Gamma$. 
Finally, we prove $\left\{u_{n}\right\} \equiv\left\{T_{r_{n}}^{f} A x_{n}\right\}$ converges weakly to $A p \in E P(f)$. Since $x_{n} \rightarrow p$, we have $A x_{n} \rightarrow A p$ as $n \rightarrow \infty$. Thus, by (3.10), we obtain $u_{n} \rightarrow A p \in E P(f)$ as $n \rightarrow \infty$. The proof is completed.

Corollary 3.1 Let $H_{1}$ and $H_{2}$ be two real Hilbert spaces. Let $T: H_{1} \rightarrow H_{1}$ be a zerodemiclosed quasi-nonexpansive mapping with $\mathcal{F}(T) \neq \emptyset$ and $f: H_{2} \times H_{2} \rightarrow \mathbb{R}$ be a bifunction with $E P(f) \neq \emptyset$. Let $A: H_{1} \rightarrow H_{2}$ be a bounded linear operator with its adjoint $B$. Given $\eta \in(0,1)$. Let $\left\{x_{n}\right\}$ and $\left\{u_{n}\right\}$ be sequences generated by

$$
\left\{\begin{array}{l}
x_{1} \in H_{1}, \\
u_{n}=T_{r_{n}}^{f} A x_{n}, \\
x_{n+1}=\left(1-\alpha_{n}\right) y_{n}+\alpha_{n} T y_{n}, \\
y_{n}=x_{n}+\varepsilon B\left(T_{r_{n}}^{f}-I\right) A x_{n}, \quad \forall n \in \mathbb{N},
\end{array}\right.
$$

where $\varepsilon \in\left(0, \frac{1}{\|B\|^{2}}\right)$ and $\left\{r_{n}\right\} \subset(0,+\infty)$ with $\liminf _{n \rightarrow \infty} r_{n}>0$. Suppose $\Gamma=\{p \in \mathcal{F}(T)$ : Ap $\in E P(f)\} \neq \emptyset$ and the control coefficient sequence $\left\{\alpha_{n}\right\}$ satisfies $\alpha_{n} \in[\eta, 1-\eta]$ for $n \in \mathbb{N}$. Then the sequence $\left\{x_{n}\right\}$ converges weakly to an element $p \in \Gamma$ and $\left\{u_{n}\right\}$ weakly to Ap $\in E P(f)$.

Next, we introduce a strong convergence algorithm for the split common solution problem.

Theorem 3.2 Let $C \subset H_{1}$ and $K \subset H_{2}$ be two nonempty, closed, and convex sets, $T: C \rightarrow$ $C$ zero-demiclosed quasi-nonexpansive mappings and $f: K \times K \rightarrow \mathbb{R}$ a bi-function with $\Gamma=\{p \in \mathcal{F}(T): A p \in E P(f)\} \neq \emptyset$. Let $A: H_{1} \rightarrow H_{2}$ be a bounded linear operator with the adjoint $B$. Given $x_{1} \in C, C_{1}=C$ and $\eta \in(0,1)$. Let $\left\{x_{n}\right\}$ and $\left\{u_{n}\right\}$ be sequences generated by

$$
\left\{\begin{array}{l}
u_{n}=T_{r_{n}}^{f} A x_{n}, \\
y_{n}=\left(1-\alpha_{n}\right) z_{n}+\alpha_{n} T z_{n}, \\
\left.z_{n}=P_{C}\left(x_{n}+\varepsilon B\left(T_{r_{n}}^{f}-I\right) A x_{n}\right)\right), \\
C_{n+1}=\left\{v \in C_{n}:\left\|y_{n}-v\right\| \leq\left\|z_{n}-v\right\| \leq\left\|x_{n}-v\right\|\right\}, \\
x_{n+1}=P_{C_{n+1}}\left(x_{1}\right), \quad n \in \mathbb{N},
\end{array}\right.
$$

where $\left\{r_{n}\right\} \subset(0,+\infty)$ with $\liminf _{n \rightarrow \infty} r_{n}>0, P_{C}$ is a projection operator from $H_{1}$ into $C$ and $\varepsilon \in\left(0, \frac{1}{\|B\|^{2}}\right)$ is a constant, $\left\{\alpha_{n}\right\}$ satisfies $\alpha_{n} \in[\eta, 1-\eta]$ for $n \in \mathbb{N}$, then $x_{n} \rightarrow p \in \Gamma$ and $u_{n} \rightarrow A p \in E P(f)$.

Proof First, we claim $\Gamma \subset C_{n}$ for $n \in \mathbb{N}$. In fact, let $p \in \Gamma$. Following the same argument as in Theorem 3.1, we have

$$
2 \varepsilon\left\langle x_{n}-p, B\left(T_{r_{n}}^{f}-I\right) A x_{n}\right\rangle \leq-\varepsilon\left\|\left(T_{r_{n}}^{f}-I\right) A x_{n}\right\|^{2},
$$

and

$$
\left\|B\left(T_{r_{n}}^{f}-I\right) A x_{n}\right\|^{2} \leq\|B\|^{2}\left\|\left(T_{r_{n}}^{f}-I\right) A x_{n}\right\|^{2} \quad \text { for any } n \in \mathbb{N}
$$


By (3.13), (3.14), and (3.15), we get

$$
\begin{aligned}
& \left\|y_{n}-p\right\|^{2} \\
& \quad \leq\left\|z_{n}-p\right\|^{2}-\left(1-\alpha_{n}\right) \alpha_{n}\left\|z_{n}-T z_{n}\right\|^{2} \\
& \quad \leq\left\|x_{n}+\varepsilon B\left(T_{r_{n}}^{f}-I\right) A x_{n}-p\right\|^{2}-\eta^{2}\left\|z_{n}-T z_{n}\right\|^{2} \\
& \quad=\left\|x_{n}-p\right\|^{2}+\left\|\varepsilon B\left(T_{r_{n}}^{f}-I\right) A x_{n}\right\|^{2}+2 \varepsilon\left(x_{n}-p, B\left(T_{r_{n}}^{f}-I\right) A x_{n}\right\rangle-\eta^{2}\left\|z_{n}-T z_{n}\right\|^{2} \\
& \quad \leq\left\|x_{n}-p\right\|^{2}+\varepsilon^{2}\|B\|^{2}\left\|\left(T_{r_{n}}^{f}-I\right) A x_{n}\right\|^{2}-\varepsilon\left\|\left(T_{r_{n}}^{f}-I\right) A x_{n}\right\|^{2}-\eta^{2}\left\|z_{n}-T z_{n}\right\|^{2} \\
& \quad \leq\left\|x_{n}-p\right\|^{2}-\varepsilon\left(1-\varepsilon\|B\|^{2}\right)\left\|\left(T_{r_{n}}^{f}-I\right) A x_{n}\right\|^{2}-\eta^{2}\left\|z_{n}-T z_{n}\right\|^{2} \\
& \quad \text { for any } n \in \mathbb{N} .
\end{aligned}
$$

Notice $\varepsilon \in\left(0, \frac{1}{\|B\|^{2}}\right), \varepsilon\left(1-\varepsilon\|B\|^{2}\right)>0$. It follows from (3.16) that

$$
\left\|y_{n}-p\right\| \leq\left\|z_{n}-p\right\| \leq\left\|x_{n}-p\right\| \quad \text { for all } n \in \mathbb{N}
$$

and hence $p \in C_{n}$ for all $n \in \mathbb{N}$. Hence, $\Gamma \subset C_{n}$ and $C_{n} \neq \emptyset$ for all $n \in \mathbb{N}$.

Now, we prove $C_{n}$ is a closed convex set for each $n \in \mathbb{N}$. It is not hard to verify that $C_{n}$ is closed for each $n \in \mathbb{N}$, so it suffices to verify that $C_{n}$ is convex for each $n \in \mathbb{N}$. Indeed, let $w_{1}, w_{2} \in C_{n+1}$. For any $\gamma \in(0,1)$, since

$$
\begin{aligned}
& \left\|y_{n}-\left(\gamma w_{1}+(1-\gamma) w_{2}\right)\right\|^{2} \\
& =\left\|\gamma\left(y_{n}-w_{1}\right)+(1-\gamma)\left(y_{n}-w_{2}\right)\right\|^{2} \\
& =\gamma\left\|y_{n}-w_{1}\right\|^{2}+(1-\gamma)\left\|y_{n}-w_{2}\right\|^{2}-\gamma(1-\gamma)\left\|w_{1}-w_{2}\right\|^{2} \\
& \quad \leq \gamma\left\|z_{n}-w_{1}\right\|^{2}+(1-\gamma)\left\|z_{n}-w_{2}\right\|^{2}-\gamma(1-\gamma)\left\|w_{1}-w_{2}\right\|^{2} \\
& \quad=\left\|z_{n}-\left(\gamma w_{1}+(1-\gamma) w_{2}\right)\right\|^{2},
\end{aligned}
$$

we have $\left\|y_{n}-\left(\gamma w_{1}+(1-\gamma) w_{2}\right)\right\| \leq\left\|z_{n}-\left(\gamma w_{1}+(1-\gamma) w_{2}\right)\right\|$. Similarly, we also have $\| z_{n}-$ $\left(\gamma w_{1}+(1-\gamma) w_{2}\right)\|\leq\| x_{n}-\left(\gamma w_{1}+(1-\gamma) w_{2}\right) \|$, which implies $\gamma w_{1}+(1-\gamma) w_{2} \in C_{n+1}$. Hence, we show that $C_{n+1}$ is a convex set for each $n \in \mathbb{N}$.

Notice that $C_{n+1} \subset C_{n}$ and $x_{n+1}=P_{C_{n+1}}\left(x_{1}\right) \subset C_{n}$, then $\left\|x_{n+1}-x_{1}\right\| \leq\left\|x_{n}-x_{1}\right\|$ for $n \in \mathbb{N}$ with $n \geq 2$. It follows that $\lim _{n \rightarrow \infty}\left\|x_{n}-x_{1}\right\|$ exists. Hence $\left\{x_{n}\right\}$ is bounded, which yields that $\left\{z_{n}\right\}$ and $\left\{y_{n}\right\}$ are bounded. For any $k, n \in \mathbb{N}$ with $k>n$, from $x_{k}=P_{C_{k}}\left(x_{1}\right) \subset C_{n}$ and the character (iii) of the projection operator $P$, we have

$$
\left\|x_{n}-x_{k}\right\|^{2}+\left\|x_{1}-x_{k}\right\|^{2}=\left\|x_{n}-P_{C_{k}}\left(x_{1}\right)\right\|^{2}+\left\|x_{1}-P_{C_{k}}\left(x_{1}\right)\right\|^{2} \leq\left\|x_{n}-x_{1}\right\|^{2} .
$$

Since $\lim _{n \rightarrow \infty}\left\|x_{n}-x_{1}\right\|$ exists, by (3.17), we have $\lim _{n \rightarrow \infty}\left\|x_{n}-x_{k}\right\|=0$, which implies that $\left\{x_{n}\right\}$ is a Cauchy sequence.

Let $x_{n} \rightarrow p$. One claim $p \in \Gamma$. Firstly, by $x_{n+1}=P_{C_{n+1}}\left(x_{0}\right) \in C_{n+1} \subset C_{n}$, from (3.13) we have

$$
\left\|y_{n}-x_{n}\right\| \leq\left\|y_{n}-x_{n+1}\right\|+\left\|x_{n+1}-x_{n}\right\| \leq 2\left\|x_{n+1}-x_{n}\right\| \rightarrow 0 \quad \text { as } n \rightarrow \infty
$$


and

$$
\left\|z_{n}-x_{n}\right\| \leq\left\|z_{n}-x_{n+1}\right\|+\left\|x_{n+1}-x_{n}\right\| \leq 2\left\|x_{n+1}-x_{n}\right\| \rightarrow 0 \quad \text { as } n \rightarrow \infty .
$$

Setting $\rho=\varepsilon\left(1-\varepsilon\|B\|^{2}\right)$, from (3.16) again, we have

$$
\begin{aligned}
\rho\left\|\left(T_{r_{n}}^{f}-I\right) A x_{n}\right\|^{2}+\eta^{2}\left\|z_{n}-T z_{n}\right\|^{2} & \leq\left\|x_{n}-p\right\|^{2}-\left\|y_{n}-p\right\|^{2} \\
& \leq\left\|x_{n}-y_{n}\right\|\left\{\left\|x_{n}-p\right\|+\left\|y_{n}-p\right\|\right\} .
\end{aligned}
$$

So

$$
\lim _{n \rightarrow \infty}\left\|T z_{n}-z_{n}\right\|=0
$$

and

$$
\lim _{n \rightarrow \infty}\left\|\left(T_{r_{n}}^{f}-I\right) A x_{n}\right\|=0
$$

Let $r>0$. Since $x_{n} \rightarrow p$ as $n \rightarrow \infty$, Lemma 2.4 and equation (3.21) imply that

$$
\begin{aligned}
\left\|T_{r}^{f} A p-A p\right\| & \leq\left\|T_{r}^{f} A p-T_{r_{n}}^{f} A x_{n}\right\|+\left\|T_{r_{n}}^{f} A x_{n}-A x_{n}\right\|+\left\|A x_{n}-A p\right\| \\
& \leq 2\left\|A x_{n}-A p\right\|+\left(1+\frac{\left|r_{n}-r\right|}{r_{n}}\right)\left\|T_{r_{n}}^{f} A x_{n}-A x_{n}\right\| \rightarrow 0 \quad \text { as } n \rightarrow \infty .
\end{aligned}
$$

So $T_{r}^{f} A p=A p$, which say that $A p \in \mathcal{F}\left(T_{r}^{f}\right)=E P(f)$. On the other hand, since $x_{n}-z_{n} \rightarrow 0$ by (3.19) and $x_{n} \rightarrow p$, we have $z_{n} \rightarrow p$. Notice that $T$ is zero-demiclosed quasi-nonexpansive mappings, by (3.20), $T p=p$, namely, $p \in \mathcal{F}(T)$. So $p \in \Gamma$. From (3.21), we also have $\left\{u_{n}\right\} \equiv$ $\left\{T_{r_{n}}^{f} A x_{n}\right\}$ converges strongly to $A p \in E P(f)$. The proof is completed.

Corollary 3.2 Let $H_{1}$ and $H_{2}$ be two real Hilbert spaces. Let $T: H_{1} \rightarrow H_{2}$ be a zerodemiclosed quasi-nonexpansive mappings with $F(T) \neq \emptyset$ and $f: H \times H \rightarrow \mathbb{R}$ be a bifunction with $E P(f) \neq \emptyset$. Let $A: H_{1} \rightarrow H_{2}$ be a bounded linear operator with the adjoint $B$. Given $x_{1} \in H_{1}, C_{1}=H_{1}$, and $\eta \in(0,1)$. Let $\left\{x_{n}\right\}$ and $\left\{u_{n}\right\}$ be sequences generated by

$$
\left\{\begin{array}{l}
u_{n}=T_{r_{n}}^{f} A x_{n}, \\
y_{n}=\left(1-\alpha_{n}\right) z_{n}+\alpha_{n} T z_{n}, \\
z_{n}=x_{n}+\varepsilon B\left(T_{r_{n}}^{f}-I\right) A x_{n}, \\
C_{n+1}=\left\{v \in C_{n}:\left\|y_{n}-v\right\| \leq\left\|z_{n}-v\right\| \leq\left\|x_{n}-v\right\|\right\}, \\
x_{n+1}=P_{C_{n+1}}\left(x_{1}\right), \quad n \in \mathbb{N},
\end{array}\right.
$$

where $\left\{r_{n}\right\} \subset(0,+\infty)$ with $\liminf _{n \rightarrow \infty} r_{n}>0$, and $\varepsilon \in\left(0, \frac{1}{\|B\|^{2}}\right)$ is a constant. Suppose that $\Gamma=\{p \in \mathcal{F}(T): A p \in E P(f)\} \neq \varnothing$ and the control coefficient sequence $\left\{\alpha_{n}\right\}$ satisfies $\alpha_{n} \in$ $[\eta, 1-\eta]$ for $n \in \mathbb{N}$, then the sequence $\left\{x_{n}\right\}$ converges strongly to an element $p \in \Gamma$ and $\left\{u_{n}\right\}$ converges strongly to $A p \in E P(f)$. 
Example 3.1 Let $H_{1}=H_{2}=\mathbb{R}$ with the inner product defined by $\langle x, y\rangle=x y$ for all $x, y \in \mathbb{R}$ and the standard norm $|\cdot|$. Let $C:=[0,+\infty)$ and $T x=\frac{x^{2}+2}{1+x}$ for all $x \in C$. From Examples 2.1 and 2.2, we know that $T$ is an zero-demiclosed quasi-nonexpansive mapping with $F(T)=\{2\}$.

Let $K:=[-\infty, 0]$ and $f_{1}(x, y)=(y-x)(x+4)$ for all $x, y \in K$, then $f$ satisfies the condition (A1)-(A4) and $E P(f)=\{-4\}$. Let $A x=-2 x$ for all $x \in \mathbb{R}$, then $A$ is a bounded linear operator with $B$ (the adjoint of $\mathrm{A}$ ) $=A$ and $\|A\|=\|B\|=2$.

Obviously, $\Gamma=\{p \in F(T): A p \in E P(f)\}=\{2\}=\mathcal{F}(T)$, so $\Gamma \neq \emptyset$. Let $x_{1} \in C,\left\{x_{n}\right\}$ and $\left\{u_{n}\right\}$ be sequences generated by

$$
\left\{\begin{array}{l}
u_{n}=T_{r_{n}}^{f} A x_{n}, \\
x_{n+1}=\left(1-\alpha_{n}\right) y_{n}+\alpha_{n} T y_{n}, \\
y_{n}=P_{C}\left(x_{n}+\frac{1}{8} B\left(T_{r_{n}}^{f}-I\right) A x_{n}\right), \quad \forall n \in \mathbb{N},
\end{array}\right.
$$

where, $r_{n}=1$ and $\alpha_{n} \in(0,1)$ for all $n \in \mathbb{N}, P_{C}$ is a projection operator from $H_{1}$ into $C$. Then the sequence $\left\{x_{n}\right\}$ converges strongly to $2 \in \Gamma$ and $\left\{u_{n}\right\}$ converges strongly to $A(2)=-4 \in$ $E P(f)$.

Proof

(i) Firstly, for given $r_{n}=1$ for $n \in \mathbb{N}$, we prove that for any $\left\{x_{n}\right\} \subset C$, there exists a unique sequence $\left\{u_{n}\right\}_{n \in \mathbb{N}} \equiv\left\{-x_{n}-2\right\}_{n \in \mathbb{N}}$ in $K$ such that

$$
f\left(u_{n}, v\right)+\left\langle v-u_{n}, u_{n}-A x_{n}\right\rangle \geq 0, \quad \forall v \in K, n \in \mathbb{N} .
$$

Because (3.24) is equivalent with

$$
\begin{aligned}
(v & \left.-u_{n}\right)\left(u_{n}+4+\left(u_{n}+2 x_{n}\right)\right) \\
& =\left(v-u_{n}\right)\left(u_{n}+4+\left(u_{n}-A x_{n}\right)\right) \geq 0, \quad \forall v \in K, n \in \mathbb{N},
\end{aligned}
$$

while (3.25) is true if and only if $u_{n}=-\left(x_{n}+2\right)$ for all $n \in \mathbb{N}$. So the conclusion is true.

(ii) Secondly, it is not hard to compute $B\left(T_{r_{n}}^{f}-I\right) A x_{n}=B\left(u_{n}-A x_{n}\right)=-2\left(x_{n}-2\right)$ for all $n \in \mathbb{N}$. Hence,

$$
x_{n}+\frac{1}{8} B\left(T_{r_{n}}^{f}-I\right) A x_{n}=\frac{3}{4} x_{n}+\frac{1}{2} \in C \text { for all } n \in \mathbb{N} \text {. }
$$

(iii) By (i) and (ii), for $x_{1} \in C$, we can rewrite the algorithm (3.23) as follows:

$$
x_{n+1}=\left(1-\alpha_{n}\right) y_{n}+\alpha_{n} T y_{n}, \quad y_{n}=\frac{3}{4} x_{n}+\frac{1}{2}
$$

and

$$
u_{n}=T_{r_{n}}^{f} A x_{n}=-\left(x_{n}+2\right), \quad \forall n \in \mathbb{N} .
$$


As in Example 2.1, we easily obtain $\left|T y_{n}-2\right| \leq\left|y_{n}-2\right|$. Hence, from (3.26) and (3.27), we get

$$
\begin{aligned}
\left|x_{n+1}-2\right| & \leq\left(1-\alpha_{n}\right)\left|y_{n}-2\right|+\alpha_{n}\left|T y_{n}-2\right| \\
& \leq\left|y_{n}-2\right|=\frac{3}{4}\left|x_{n}-2\right| \\
& \leq \cdots \\
& \leq\left(\frac{3}{4}\right)^{n}\left|x_{1}-2\right|, \quad \forall n \in \mathbb{N}
\end{aligned}
$$

which shows $x_{n} \rightarrow 2 \in \mathcal{F}(T)=\Gamma$. Since $u_{n}=-\left(x_{n}+2\right), n \in \mathbb{N}$, we obtain $u_{n} \rightarrow-4=A(2) \in E P(f)$.

\section{Competing interests}

The authors declare that they have no competing interests.

\section{Authors' contributions}

Both authors contributed equally and significantly in writing this paper. Both authors read and approved the final manuscript.

\section{Author details}

${ }^{1}$ Department of Mathematics, Honghe University, Yunnan, 661100, China. ${ }^{2}$ Department of Mathematics, National Kaohsiung Normal University, Kaohsiung, 824, Taiwan.

\section{Acknowledgements}

The authors would like to express their sincere thanks to the anonymous referee for their valuable comments and useful suggestions in improving the paper. The first author was supported by the Natural Science Foundation of Yunnan Province (2010ZC152). The second author was supported partially by Grant no. NSC 100-2115-M-017-001 of the National Science Council of the Republic of China.

\section{Received: 21 April 2012 Accepted: 26 July 2012 Published: 6 August 2012}

\section{References}

1. Blum, E, Oettli, W: From optimization and variational inequalities to equilibrium problems. Math. Stud. 63, 123-145 (1994)

2. Moudafi, A, Théra, M: Proximal and dynamical approaches to equilibrium problems. In: III-posed Variational Problems and Regularization Techniques. Lecture Notes in Economics and Mathematical Systems, vol. 477, pp. 187-201. Springer, Berlin (1999)

3. Combettes, PL, Hirstoaga, A: Equilibrium programming in Hilbert spaces. J. Nonlinear Convex Anal. 6, 117-136 (2005)

4. Flam, SD, Antipin, AS: Equilibrium programming using proximal-link algorithms. Math. Program. 78, $29-41$ (1997)

5. Takahashi, S, Takahashi, W: Viscosity approximation methods for equilibrium problems and fixed point problems in Hilbert spaces. J. Math. Anal. Appl. 331, 506-515 (2007)

6. Kangtunyakarn, A, Suantai, S: A new mapping for finding common solutions of equilibrium problems and fixed point problems of finite family of nonexpansive mappings. Nonlinear Anal. 71, 4448-4460 (2009)

7. Qin, X, Cho, YJ, Kang, SM: Convergence theorems of common elements for equilibrium problems and fixed point problems in Banach spaces. J. Comput. Appl. Math. 225, 20-30 (2009)

8. Saeidi, S: Iterative algorithms for finding common solutions of variational inequalities and systems of equilibrium problems and fixed points of families and semigroups of nonexpansive mappings. Nonlinear Anal. 70, 4195-4208 (2009)

9. Chang, SS, Lee, JHW, Chan, CK: A new method for solving equilibrium problem fixed point problem and variational inequality problem with application to optimization. Nonlinear Anal. 70, 3307-3319 (2009)

10. Jung, JS: Strong convergence of composite iterative methods for equilibrium problems and fixed point problems. Appl. Math. Comput. 213, 498-505 (2009)

11. Zegeye, H, Ofoedu, EU: Convergence theorems for equilibrium problem, variational inequality problem and countably infinite relatively quasi-nonexpansive mappings. Appl. Math. Comput. 12, 3439-3449 (2010)

12. Colao, V, Marino, G, Xu, H-K: An iterative method for finding common solutions of equilibrium and fixed point problems. J. Math. Anal. Appl. 344, 340-352 (2008)

13. Yao, Y, Liou, YC, Yao, JC: Convergence theorem for equilibrium problems and fixed point problems of infinite family of nonexpansive mappings. Fixed Point Theory Appl. 2007, Article ID 64363 (2007)

14. He, Z, Du, W-S: Strong convergence theorems for equilibrium problems and fixed point problems: a new iterative method, some comments and applications. Fixed Point Theory Appl. 2011, 33 (2011) 
15. He, Z: A new iterative scheme for equilibrium problems and fixed point problems of strict pseudo-contractive mappings and its application. Math. Commun. (in press)

16. Moudafi, A: A note on the split common fixed-point problem for quasi-nonexpansive operators. Nonlinear Anal. 74 4083-4087 (2011)

17. He, Z, Du, W-S: On split common solution problems for nonlinear operators (submitted)

18. He, Z: The split equilibrium problem and its convergence algorithms. J. Inequal. Appl. 2012, 162 (2012). doi:10.1186/1029-242X-2012-162

doi:10.1186/1687-1812-2012-130

Cite this article as: He and Du: Nonlinear algorithms approach to split common solution problems. Fixed Point Theory and Applications 2012 2012:130.

Submit your manuscript to a SpringerOpen ${ }^{\circ}$ journal and benefit from:

- Convenient online submission

- Rigorous peer review

- Immediate publication on acceptance

- Open access: articles freely available online

- High visibility within the field

- Retaining the copyright to your article

Submit your next manuscript at $>$ springeropen.com 